\title{
To integrate or not to integrate? A matter of choice for universities
}

\author{
Luísa Cannas da Silva*(D) \\ Teresa Valsassina Heitor**:D
}

\begin{abstract}
What is the right location for a university campus? Universities have a preponderant role in today's societal models. They have been in the core of development economic, social, sustainable, inter alia - and their role within urban context has changed in order to respond to the university mission - that nowadays includes of civic engagement as well as a stronger participation in economies, through the development of startups and innovation ecosystems. This paper relies on the premise that, even in a post-pandemic world, the Campus is still a window to the world, it can shape the perception people have of the University, can be used as a branding asset and, most of all, impacts the lives of everyone living, learning, and working there. The Campus is a very powerful tool, one that universities worldwide have been using as a way of positioning themselves, of attracting students and faculty, and also creating synergies and relationships with companies. It shapes the relationships created inside and outside of it. As such, this research argues that universities can be key elements in generating and enabling dynamic synergies, promoting the presence of students, academics, and learning spaces in urban contexts. To accomplish this, universities should preserve their spatial identity and uniqueness, while guaranteeing the existence of adequate places for all learning related activities and embodying inclusion and sustainable development, promoting encounters and interaction. These two needs, for inclusion and livelihood while safeguarding some privacy coexist creating some tension for all campus users. With this issue in mind, this paper explores an analytical framework for university campuses within urban fabrics, understanding the different types of urban insertion and connections established with local and regional players, and exploring the dichotomy between closeness centrality and betweenness centrality, as variables than can be used to balance the tension between integration and privacy that affects university campuses and academic communities worldwide. Four compact university campuses that host similar functions are used to test the methodology: Simon Fraser University in Burnaby, Canada; Aalto University in Espoo, Finland; MIT in Cambridge, MA, USA; and Yale University, in New Haven, USA. This paper relies on syntactic analysis to provide deeper information and some clarification on the university location and accessibility within the urban fabrics.
\end{abstract}

Keywords: university campus, integration, choice, centrality, university synergies.

\section{Introduction}

Universities have always played a dominant role in modern societies. The effect of university facilities in urban dynamics has progressively become more complex, affecting directly all users 
(academia and non-academia), and reaching all spheres of society. Merely their physical presence is already an element of change. University activities impact in many ways their vicinity and wider communities to the mutual benefit of both (Knight 1995, den Heijer 2011), interfering in the process of urban development, in parameters such as employment, housing, mobility, leisure and consumer activities (Indovina 1997). As central elements in the economy, universities can contribute to urban regeneration, not only directly by improving the built environment quality, but also reclaiming city areas and funds from public regional players. Today's idea of university shows an entrepreneurial entity, able to actively contribute for the social fabric and engaging in social, economic and cultural challenges (Corneil and Parsons 2007).

As Temple $(2009,2014)$ advocates, the physical space is one of the most powerful tools available for the university to express and convey its identity, namely its values, mission and cultural background. Not only is the university able to express its identity through the physical space (Edwards 2003, Hajrasouliha and Ewing 2016), but it can also communicate its presence, purpose and domain (Dober 1992). Furthermore, campus configuration, including proximity and adjacency relationships, can foster exposure and interactions that permit successful collaborations and outputs (Kenney et al. 2005).

Several authors emphasise the importance of establishing relationships, connections and synergies between university campuses and their host cities (Gibbons et al. 1994, Conceição and Heitor 1999, Duderstadt 2002, Christiaanse and Hoeger 2007, den Heijer 2011, Campos CalvoSotelo 2015). Nevertheless, there is a shortage of literature focusing on the description of the spatial properties that enable these relationships and which may, in particular, contribute towards supporting urban activity and vitality in a balanced and sustainable manner, i.e. without forgetting that university precincts are academic facilities requiring a spatial identity that guarantees adequate places for learning and its related intellectual activities.

According to Engwicht. "cities were invented to facilitate exchange of information, friendship, material goods, culture, knowledge, insight, skills, and also the exchange of emotional, psychological, and spiritual support" (1992, p. 17). And so were university precincts. Space quality can inform and impact on human behaviour and activity, and there is a close connection between the qualities of the urban space and the quality of the activities performed there (Whyte 1980, Beck 2009). One can argue that there is a close connection between the quality of a university's physical space and the quality of university life.

Nevertheless, universities throughout history have experienced several different movements of approximation and isolation towards their hosting cities. From generating urban fabric and enabling interaction, to moving away from city centers, generating heavy and unsustainable commuting movements, universities have been shifting from ivory tower to engaged institution at different times and contexts.

This paper examines the configurational features that can contribute positively to the integration and development of university precincts in urban \& social areas. The purpose is to identify location properties that influence the campus' ability to become integrated and embedded in its urban setting. University campuses are defined as the areas occupied by a university and where its functions and activities take place. In the scope of this paper, only campuses that host all activities consentaneous with the presence of people on a $24 / 7$ basis were considered. The cases were chosen from a larger sample, and each of them is representative of a type of university precinct according to their morphological features (Cannas da Silva 2017).

\section{Methodology}

Space syntax theory aims at understanding the performance of built environments (Hillier et al. 1983) and its ability for hosting human activities and functions by relating social variables to built 
spaces, through a precise method of description. It relies on the premise that space has social implications and affects users' behaviours and the possibility to shape interactions, since the system structure of space in which various activities occur can influence movement, encounter, and avoidance, as well as generates social relations (Hillier and Hanson 1984).

Space Syntax provides a method to describe space by means of a measurable, non-arbitrary and reproducible representation (Heitor and Pinelo Silva 2015) in which built spaces (ranging from buildings to cities) are defined as configurations, i.e., elements in a relational environment, evaluated according to the relationships they establish.

It considers space in terms of abstract properties of topological nature rather than in terms of geometric measures. Thus, spatial layouts are described regarding the pattern of connections between spaces and the extent to which each space is directly connected to other spaces, i.e. how far each element is from all others, according to a specified measure of distance; and, how many paths run through each element (Peponis 2016, p. 39).

The axial map is a simplification of the city's pattern through "the most parsimonious set of straight lines that intersect to form a network covering all possible ways of moving around the city" (Peponis 2016, p. 38). This representation covers lines of physical and visual continuity among interconnected spaces, since when analysing urban space, movement is regarded as the basic function of street spaces, and so spaces are reduced to "the longest accessible lines that cover all convex spaces in a map"(Al-Sayed et al. 2014). The axial map description operates as a macro analysis of the urban structure. It allows for an even representation of information in topological relationship and with assessable horizontal distances, whether these distances might be topological, metric or angular.

Segment maps are a derivation of axial maps later introduced by Turner (2004) which considers the segment as the elementary components of the street network. Street segments consist of the segment section between two intersection points. For instance, an axial line that is intersected by two others is composed of three segments, and thus, when analysed in a segment map, each of the three sections is considered as one element in the system. One of the key aspects of segment analysis is that they enable analysis on angular distances, becoming a very powerful tool to emulate the perception of streets continuity and assess how much energy is spent along a trip or when one moves from one space to another one.

Space syntax allows for a diverse range of analysis (Heitor and Serra 2016). In this research, it is used to analyse the universities position within the surrounding urban system and explore to what extent the university precinct is integrated in the urban fabric and has the potential for crossexchanges. Thus, in this paper, axial maps and segment maps are used, and the focus is on two main variables: closeness centrality - integration; and betweeness centrality - choice.

Closeness centrality - integration represents the distance from each object in the system (each axial line) to all the others, characterizing the relationships among lines according to the number of changes in direction from each element to all the other within the system. This analysis evaluates each visual segment from more segregated (located deeper in the system, i.e., needing more changes in direction in order to be reached from all other locations) to more integrated, i.e., reached within fewest changes in direction.

Betweeness centrality - choice, measures the "quantity of movement that passes through each spatial element on shortest or simplest trips between all pairs of spatial elements in a system" (Hillier et al. 2012). Thus, integration - closeness - represents the "to-movement potential of a space", while choice - betweeness - represents the "through-movement potential" (Hillier et al. 2012). 
Integration allows measuring the easiness in access from any other point in the system, showing the potential of the university surroundings to be a destination, or rather, showing whether the university premises are in a place with the potential to be a destination in random movements. Choice, in opposition, shows the potential of the university premises to be in a place that enables "passing by" movement, that is, that is usually used in random dislocations from origins and to destinations that do not include the university's location. The higher the choice value of a place, the more the line or segment where it is located is on the path of movement between all pairs of spatial elements within the system, that is, the more movement crosses it on shortest or simplest trips within the system. This measure approximates the university's potential to enable serendipitous relationships between academics and outside users.

Space Syntax analysis of the sample of university precincts was carried out in three steps: 1) the representation of the spatial elements and their relationships by means of axial map and segment map; 2 ) the analysis of these elements and relationships among them.

Integration and choice are dimensionless, so they are not evaluated in any unit. They rely on the graph defined by all street lines, considered nodes, and their intersections, considered connections. Therefore, even when the maps present a metric scale, that does not apply to the analysis of integration, and does not change it. It just allows for comparison regarding the dimensions of the systems analysed.

Attempts to normalize choice and integration in order to enable comparing different cities were made by Hillier and Yang (Hillier et al. 2012). These normalized variables refer exclusively to segment maps, for the possibilities this measures enable, and are based on angular choice and integration. These two variables - Normalized angular choice (NACH) and normalized angular integration (NAIN) - represent a development in the field of space syntax that starts from integration and choice and permits to compare results among different cities. Besides, segment maps, and particularly angular analysis have proven to be quite accurate when it comes to evaluate street movement potential (Hillier et al. 2012). Moreover these normalized variables have proven to be strongly correlated with movement (Hillier et al. 2012) and thus provide additional clarification on the movement potential of the places where university premises are located.

Thus, segment maps were used as the basis for comparison and normalized angular choice (NACH) and normalized angular integration (NAIN) were applied, to complement the axial analyses of integration and choice.

In this section, all cities and university campuses are analysed in comparison, in terms of their foreground and background structures, to justify the university's presence in urban dynamics, according to its location and insertion in the city's structure. Cities present a dual structure through which all activity and movement flow. This dual structure, divided into "foreground network" and "background network", each of them with specific topological, metric and geometric properties (Hillier 2014). The "foreground" consists of the network that links all the centres at all scales, i.e. the skeleton, while the "background", though nested in the foreground, is mostly made of neighbourhood areas, with a focus on the residential and all related functions. While the former is made of longer and straighter lines, derives from micro-economic activity, grounded on invariant principles, and tends to assume a generic form, the latter relies on shorter segments, with mostly right angles among them, creating a grid-like structure which relies strongly on social and cultural factors (Hillier 2014). Therefore, while the foreground network is organized to achieve maximum movement potential and thus tends to be highly integrated, the background network behaves in a more secluded way. Since the background includes most segments in a system, it can be represented by the mean values obtained for any variable.

On this study, this analysis allows to understand whether a university is positioned within the foreground or the background network of its hosting city, thus informing on its character and movement attraction potential. When a university is in the foreground network it is likely to be 
highly crossed by on random travels, to be visible within the urban system, to behave as a landmark and a reference point within the city. Opposing, when a university precinct is located within the background network it tends to be more appropriated by the neighbourhood and more likely to be used as part of it but can be disregarded as an important element for the city at a global scale. Hence, it is less likely to be used as a path on random movements, but rather to be reached only if it is a destination. In all cases, university premises do not have the structure to be part of the foreground network. Rather, their precincts are an integrant part the background network. It is the proximity to the foreground, or the fact that some of the segments included in the university precinct are part of the foreground network that changes its likelihood to be used as a path by external users.

The analysis of $\mathrm{NACH}$ gives information on the structure of the urban system. The mean $\mathrm{NACH}$ informs on the degree to which the background network forms a continuous grid with direct connections (Hillier et al. 2012) while the maximum NACH informs on how the foreground network structures the system. The higher the value of maximum NACH, the more structured a system is. Similarly, the higher the mean NACH is, the more continuous the background structure is.

NAIN, on the other hand, gives information on the ease of accessibility, that is, on proximity among segments. Maximum NAIN represents the ease of accessibility in the foreground network, while the mean value represents the same factor in the background network. A summary of the information comprised in this values can be found in the table below.

Table $1 \mathrm{NACH}$ and NAIN variables and their meaning

\begin{tabular}{|l|l|l|}
\hline & Mean & Maximum \\
\hline NAIN & To-movement potential Background network & To-movement potential Foreground network \\
\hline NACH & Through-movement potential Background network & $\begin{array}{l}\text { Through-movement potential Foreground } \\
\text { network }\end{array}$ \\
\hline
\end{tabular}

Hillier and Yang (Hillier et al. 2012) refer that the the maximum value of NACH for small systems can be around 1.4, but that, in general, this value reaches numbers between 1.5 and 1.6 or even slightly higher. This would be the case in cities with a strong structure. The mean value for $\mathrm{NACH}$ usually falls between 0.7 and 1.2, the more regular the grid, the highest this number.

To provide a comparison, segment maps were developed for each of the case studies. For the $\mathrm{NACH}$ analysis the colour gradation was adjusted to make them comparable, adjusting the blue values to below 0.8 and the red values to above 1.4 , which corresponds to the foreground structure to make it more visible. For the NAIN analysis, the maps present a colour gradation by quantiles, that is, the same percentage of each colour is visible in the map, making them easier to compare.

\section{Analysis and Results}

Four university campuses and hosting cities are analysed. These cases were chosen as a part of a larger research (Cannas da Silva 2017), and they represent a specific campus typology which considers the precinct as an (almost) autonomous entity - campus as a city.

These campuses supply everything needed to host the main functions of the university and support the continuous presence of people. The campus hosts not only the learning, researching and some leisure activities, but also all the functions that support the living activities of its population (for instance, residences or halls, canteens, medical services, and so forth). These precincts attempt to shield their users from exterior disturbances and activities. Nevertheless, in most cases, they also welcome outside users. They can either be in the outskirts or even outside urban regions, but they can also be established within the tissue of the hosting city. Still, they can establish themselves as independent entities, which could function almost autonomously. The first two types are inner focused - the precinct is closed over itself - while the last two are outward focused, that is, is opened to the exterior environment, allowing for visibility and permeability. 


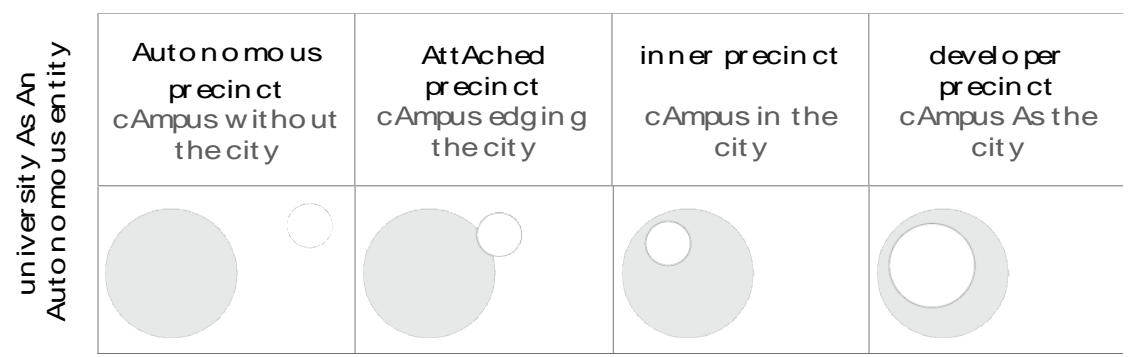

Figure 1 Types of university campuses that function as autonomous entities

3.1. Simon Fraser University - Burnaby, Canada, 1965

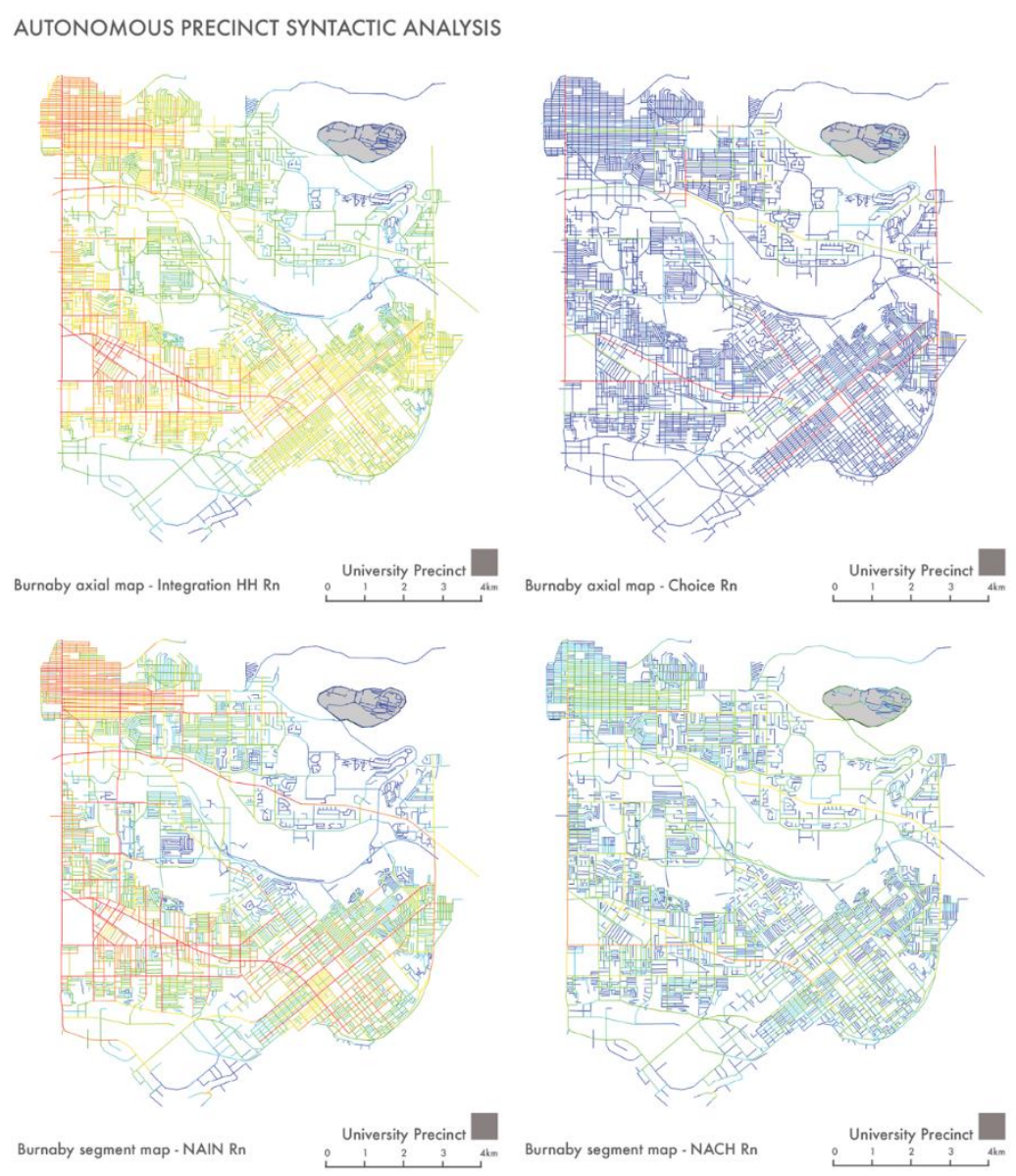

Figure 2 Burnaby Axial and Segment Maps - Simon Fraser University Campus Assessment

The most integrated streets on the network are in the north-western and south-western sections of the city. The university campus, located on the northeastern area of the city, appears in one of the most segregated areas.

The city presents a mean Integration value of 0.7593 , showing 0 as minimum value and as maximum 1.1057 (an integration range of 1.1057). The values above the 3rd quartile (making the 4 th quartile), i.e., the $25 \%$ more integrated areas, show values of 0.8718 or higher.

The university, identified in a grey shadow, presents integration values below the average of the city. The sum of the axes that are encompassed by the area of the university present an average integration value of approximately $54 \%$ of the average integration value for the whole system. The university is in the $25 \%$ less integrated streets in the network of Burnaby. 
The analysis of choice enhances the results of integration. As can be observed in the figure, the lines which present the highest values of choice correspond mainly to highly integrated areas.

The university precinct does not include any axial line with a relevant choice value, which means it has a very low probability of being crossed on travels that do not include the university as either an origin or a destination. Nevertheless, its main access shows a choice value above the average of the system and occupies the $25 \%$ of streets more likely to be passed through on random travels. Despite this value, for the location of the university on the top of the Burnaby Mountain, it is unlikely that the access to the university is used by travellers on random travels not aiming to reach the university.

Burnaby presents a mean NACH of 0.911, at a global scale (Rn) and a maximum value of 1.606, while the sum of the segments comprised within Simon Fraser University's precinct, reaches a maximum value of 1.289 and a mean value of 0.815 . In terms of NAIN, the city presents a mean value of 1.069 and a maximum of 1.652 while the precinct shows a mean value of 0.571 and a maximum value of 0.862 .

These results are consistent with those obtained in the axial analysis, emphasizing the segregation of the university precinct and its low probability of being crossed in random travels.

Despite this fact, the city of Burnaby presents a strong structure, as proved by its values of maximum and mean $\mathrm{NACH}$. The background structure seems more relevant than the foreground, depicting the foreground structure as almost encircling the city, much more dominant on the western edge, limited by the city of Vancouver.

\subsection{Aalto University - Otaniemi Campus - Espoo, Finland, 1961}

ATTACHED PRECINCT SYNTACTIC ANALYSIS
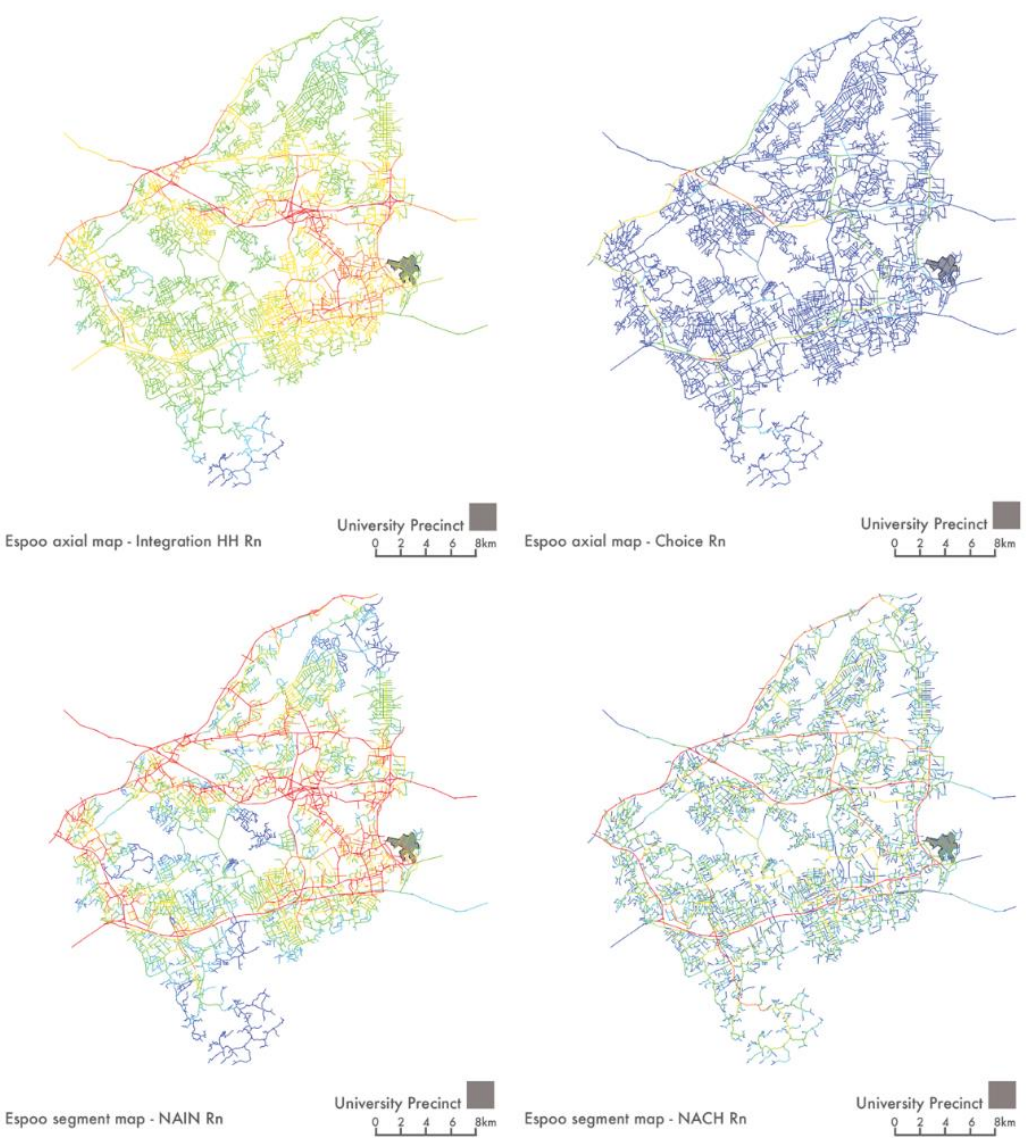

Figure 3 Espoo Axial and Segment Maps - Aalto University Campus Otaniemi Assessment 
The analysis of Aalto University considers Espoo as the hosting city, even though both Espoo and the campus benefit from the proximity with the city of Helsinki. From the map analysis it becomes clear that the more integrated streets on the network are in the western sections of the city, which are also the ones connecting Espoo to the capital.

The city presents a mean Integration of 0.2788068 , showing as minimum value 0.11367346 and as maximum 0.39258346 , which shows a very small range for integration values, of 0.27891 . The values above the $3 r$ d quartile, i.e., the $25 \%$ more integrated areas, show values of 0.3098369 or higher.

The university, identified in a grey shadow, presents integration values above the average of the city. The sum of the axes that are encompassed by the area of the university present an average integration value 0.02 points higher than the average for the whole system. The university is located in the $40 \%$ more integrated streets in the network of Espoo.

The analysis of choice shows the dominance of a structural network system connecting Espoo to its adjacent municipalities on the east and west and linking the city from north to south. Aalto university campus is located beside some of the important axes, nevertheless it is not crossed or encircled by any of those, granting it some privacy while ensuring very good road accessibility.

The university campus presents lower choice values, which places its segments on the $75 \%$ more likely to be walked through paths.

The main access presents a choice value among the $25 \%$ with highest values within the system.

The location of the precinct, beside the main bridge connecting Espoo to Helsinki, is likely to increase the traffic near or within the precinct, since this bridge is one of the important entry points in the capital from Espoo.

Espoo presents a mean $\mathrm{NACH}$ of 0.603 , at a global scale $(\mathrm{Rn})$ and a maximum value of 1.509 , while the sum of the segments comprised within the Otaniemi precinct, reaches a maximum value of 1.209 and a mean value of 0.741 . In terms of NAIN, the city presents a mean value of 0.452 and a maximum of 0.693 while the precinct shows a mean value of 0.488 and a maximum value of 0.581 . Espoo presents the lowest values of the set for both mean NACH and mean NAIN, which is representative of the high fragmentation of the city's structure, and the weakness of the background network, strongly relying on the foreground to become interconnected. The foreground network also presents low values compared to the other cases. The city of Espoo presents the lowest value of maximum NAIN when compared to the other cities in the set.

Such low values can be explained by the system's configuration, since NACH can present rather low values when measuring systems in areas not yet fully developed or unurbanized. Even though this is not the case of Espoo, the city's two-dimensional configuration might appear similar to that of an unurbanized region, with several discontinuities, for the fragmentation of its territory, mostly caused by the presence of several water bodies and other natural elements.

Nevertheless, the university precinct is in a predominant area, showing rather high values of both NACH and NAIN at a global scale. Thus, the potential of movement in both to- and through travels around the Otaniemi precinct is very high, making it a very accessible destination, but also probably a highly crossed elements in random travels not including it, rendering the university very visible throughout the community, especially those who commute to and from Helsinki. 


\subsection{Massachusetts Institute of Technology-Cambridge, MA, USA, 1916}

INNER PRECINCT SYNTACTIC ANALYSIS
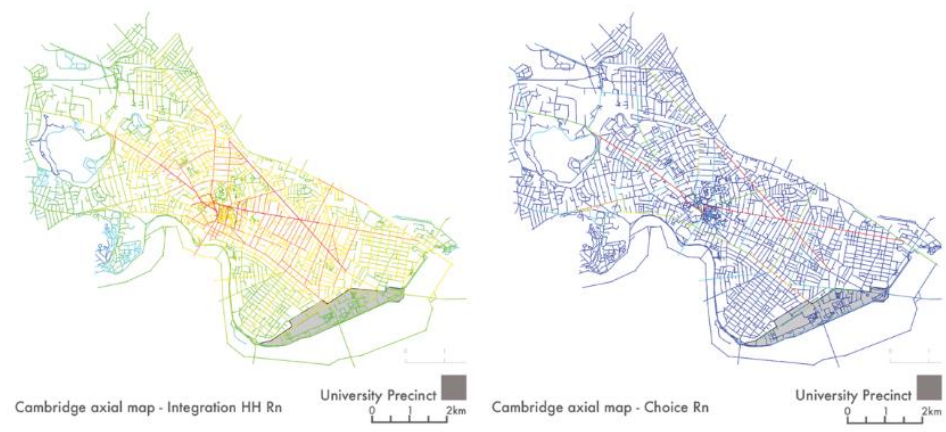

Page | 82
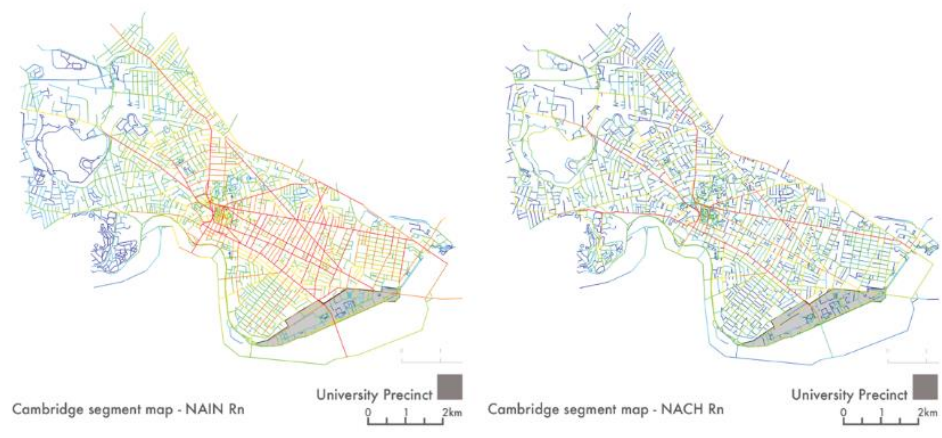

Figure 4 Cambridge, Massachusetts axial and segment maps and MIT Campus Assessment

The axial map of Cambridge shows the integration core in the central area of Harvard Square and Harvard Yard, emphasizing east-west connections towards Boston.

The city presents a mean integration of 0.7607691 , showing a minimum value 0.19885656 and a maximum integration of 1.1969923. Therefore, integration in Cambridge has a range of 0.9981357 . Streets with integration levels above the 3 rd quartile of values, i.e., the $25 \%$ more integrated areas, show values of 0.8870931 or higher.

The precinct of MIT, identified in a grey shadow, presents integration values slightly below the average of the city. Even though the precinct is fully inserted within the city's fabric, its location at the edge and by the river contributes for this situation. Nevertheless, if we consider the full metropolitan area of Boston the results will be dramatically different and the axes that encircle and cross MIT's precinct would present much higher integration results. The sum of the axes that are encompassed by the area of the university present an average integration value approximately 0,4 points below the average for the whole system, which places MIT in the $75 \%$ more integrated areas.

The analysis of choice reiterates the importance of the integration core, since the streets that present higher integration values also present the highest choice values. Since choice is a good movement predictor, it is arguable that these streets are not only easy to reach but also successful in attracting flows of movement and activities.

The university campus presents lower choice values, in the 2 nd quartile of values, although its main access is one of the $25 \%$ axes with higher values within the system.

In a broader map, probably the university would attain higher choice values, especially on the segment identified as main access, mainly because of its proximity to the bridges connecting to the centre of Boston. Nevertheless, and considering only the limits of the municipality, the MIT's precinct doesn't show a high probability of being walked through on the way to any other destiny. 
Cambridge presents a mean NACH of 0.892 , at a global scale (Rn) and a maximum value of 1.564 , while the sum of the segments comprised within the MIT precinct, reaches a maximum value of 1.401 and a mean value of 0.858 . In terms of NAIN, the city presents a mean value of 1.023 and a maximum of 1.631 while the precinct shows a mean value of 0.975 and a maximum value of 1.470.

Cambridge presents the highest value of mean NACH for a city after Burnaby, which is consistent with a very strong background structure, with few discontinuities, but rather several direct connections, on a grid-like system. Maximum NACH for the city of Cambridge reaches a usual value, and the city presents a strong structure, grounded on the foreground network, which unifies the foreground and acts as main connector to the adjacent municipalities.

MIT presents very similar (even though slightly lower) values of NACH in comparison with the city of Cambridge.

As can be observed in these maps, MIT presents a structure similar of that of a city, with foreground and background networks within the precinct. Its main axes, presenting higher values of both NACH and NAIN are and integrant part of the city's foreground network, presenting strong potential of both to- and through-movement. Its internal structure, consistent with typical background network in the city of Cambridge, acts as a neighbourhood, less intelligible and harder to read than the main axes, and creating more segregated areas, shielding the interior of the university precinct from the outside. In terms of NAIN values, the precinct shows also very similar results to those of the city when analysing the mean value, and a maximum value slightly lower than the city, but still showing a strong difference from the mean values, which emphasizes its dual structure of foreground and background in terms of urban configuration. It is remarkable the proximity in terms of values between the city of Cambridge and MIT, making the precinct a good representation for the city, i.e., an element from which the city's structure can be perceived.

\subsection{Yale University - New Haven, CT, USA, 1716}

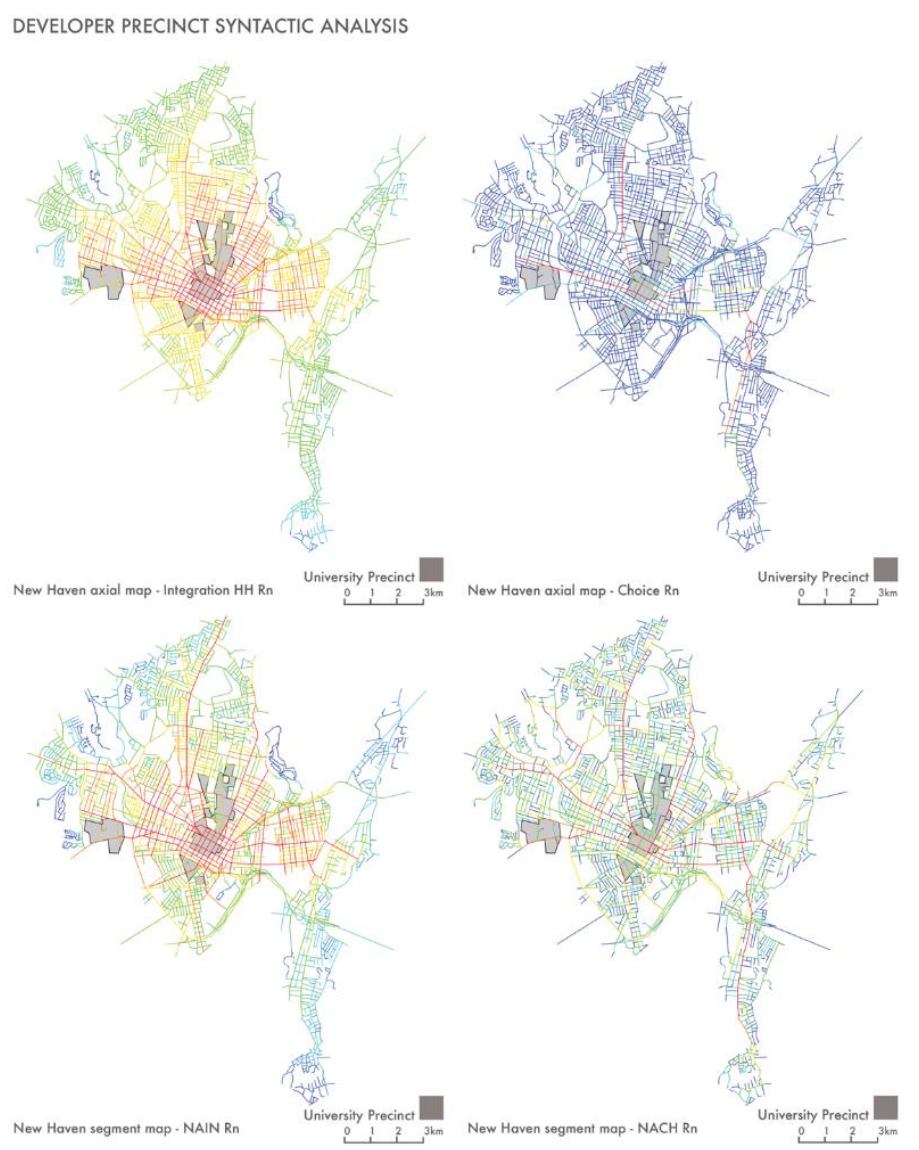


The city of New Haven developed from and because of the university, and that justifies the fact that the university is in the integration core, and alongside the most important expansion axes. In fact, on the city's development, the university and the church occupied the most prominent areas within the city, besides the main yard, in the centre of New Haven.

New Haven presents an integration range of 0.764713849 , from a minimum value of 0.13960013 to a maximum of 0.90431398 . The mean value for the integration in the city is 0.56135328 . The third quartile of values reaches a value of 0.689776334 . The sum of the axes that are inscribed and around the university grounds presents an average value of 0.763369499 , placing the university axial lines on the integration core, within the $25 \%$ more integrated areas.

In terms of choice, a distinction in the axes encircling or connecting to the university premises is perceived, especially in its central areas.

The university premises present a choice value much higher than the average of the city, even above the limit of the 3rd quartile of choice values, placing the university premises within the $25 \%$ axes more prone to be used in random travels not originating or terminating in campus.

The main access of the university campus (in the scope of this paper, it was considered College Street as the main access), is one of the segments within the $25 \%$ axes with higher choice.

New Haven presents a mean NACH value of 0.820 and a maximum value of 1.594 at a global scale. The precinct of Yale university presents a mean NACH value of 0.999 and a maximum pf 1.594 as well as the city, since the segment with the highest value is located within the university's precinct. As far as NAIN is concerned, the city presents a mean value of 0.857 and a maximum of 1.365 , and the university precinct shows a mean value of 1.074 and the same maximum value of the city. Again, the most integrated segment is included within the university precinct. These very high integration levels make the precinct of Yale University an area with very high to-movement potential.

The precinct of Yale university presents the second highest mean NACH value of the set of case studies, much higher than the value presented by the city of New Haven. This places the University precinct in-between background and foreground network, with some of its axes clearly belonging to the latter, and several others being on the transition between both or acting as dual elements, with a strong presence in local life, but also important at a global scale.

It also presents the highest value of $\mathrm{NACH}$ among the selected university precincts, making it the one with stronger through-movement potential within this set. It justifies and is justified by the deep relation between university and city, and is consistent with this type of cases, in which university and city are intertwined and develop through one-another. This gives the university the potential to attract a wide range of users, businesses, and activities to its area.

\section{Discussion}

The results of the axial analysis are summarized in the tables below:

Table 2 Axial analysis summary

\begin{tabular}{|c|c|c|c|c|c|c|c|}
\hline City & $\begin{array}{c}\text { City axial } \\
\text { lines }\end{array}$ & $\begin{array}{c}\text { University } \\
\text { axial lines }\end{array}$ & $\begin{array}{c}\text { \% of } \\
\text { area }\end{array}$ & $\begin{array}{c}\text { University mean } \\
\text { integration }\end{array}$ & $\begin{array}{c}\text { Main access } \\
\text { integration }\end{array}$ & $\begin{array}{c}\text { University mean } \\
\text { choice }\end{array}$ & $\begin{array}{c}\text { Main access } \\
\text { choice }\end{array}$ \\
\hline Burnaby & 3941 & 147 & 4 & 1st quartile & 1st quartile & 3rd quartile & 4th quartile \\
\hline $\begin{array}{c}\text { Espoo } \\
\text { Cambri } \\
\text { dge }\end{array}$ & 6440 & 42 & 0,7 & 3rd quartile & 3rd quartile & 2nd quartile & 4th quartile \\
\hline $\begin{array}{c}\text { New } \\
\text { Haven }\end{array}$ & 2360 & 106 & 4 & 2nd quartile & 3rd quartile & 2nd quartile & 4th quartile \\
\hline
\end{tabular}




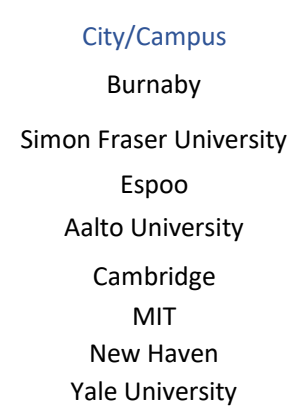

MEAN NACH RN
0,911
0,815
0,603
0,741
0,892
0,858
0,820
0,999

Table 3 Segment Analysis Summary

The percentage of axial lines the universities occupy vary substantially, from $0,7 \%$ of the total of the city, in the case of Espoo, to 8\% of the urban region, in the case of Cambridge. This value alone is not an accountable measure of the university's impact on the area, nevertheless it clearly affects university's visibility and its influence in urban politics and other dynamics, for the fraction it occupies and dominates within the urban territory.

The case of Burnaby - an autonomous precinct - shows very low integration values within the city, but high choice values. This means that the precinct is probably not used by the exterior community as part of their environment, but rather passed by in travels across the Burnaby Mountain. Nevertheless, the university's character of behaving as a "city in a microcosm" (Turner 1984) appears justified in its internal structure, with a foreground and background network of its own when considering smaller radii of analysis.

Espoo - an attached precinct - shows a mean integration value above the average of the city, and low mean choice within the precinct, despite the very high value of choice of its main access. These values are probably influenced by the fragmentation of the urban fabric of the city, since it would be expected that the mean integration of the precinct was lower. The values of choice, however, are easier to explain. Within the precinct, most of the streets do not belong to the shortest path among origins in destinations for the whole system, nevertheless, the main access considered is one of the few axes connecting Espoo to Helsinki, on the East, especially on the southern area of both cities. In a more comprehensive map, probably the values of choice of this region would be much higher.

The whole city presents the lowest values of mean NACH and NAIN, representative of a very weak background structure, and a very fragmented fabric. In this case, the foreground structure becomes more relevant, being used in most travels between different areas, since it assumes a very important connection role among areas. Since the precinct is in an adjacent area to the foreground network, it becomes more visible and likely to be visited in travels. The precinct itself behaves as background network and presents similar dimensions than many of the other fragmented sections of the urban territory, behaving as a unit within the fabric. The fact that the values of mean $\mathrm{NACH}$ and NAIN for the precinct are slightly higher than the ones observed when analysing the whole city, is a reflex of the structure of the precinct, as a (less weak than the average of the city) urban unit.

The case of Cambridge - an inner precinct - is distinct than the others. On the one hand, the presence of the university exceeds that of MIT, since Harvard University also occupies an important position within the city. Together, they add up to a very large portion of the urban fabric, and consequentially, of the axial lines. In this particular case, the university becomes extremely relevant for the context where it is inserted, and both universities benefit from the presence and direct competition of the other. However, considering only MIT, both mean integration and mean choice do not present very high levels, probably due to its location at the edge of the city. If we consider greater Boston instead of Cambridge as limits for the urban region, however, results will be very different, and MIT will occupy the centre of the region. Nevertheless, and considering the importance of MIT and its precinct for the cities of Cambridge and Boston, its low integration and choice do not diminish its urban capacity and urban attractiveness, since the precinct can act as an 
attractor and a generator of movement. Still, if we consider its topological accessibility solely, and disregard the fact that MIT's premises are landmarks within the city of Cambridge, the precinct is in an area that does not enable its visibility or make it an attractive destination within the surroundings for external users.

Despite its openness and its central location, close to the integration core, MIT presents an urban structure of its own, with a foreground network on the main campus axis, and a background network composing its inner territory. This dual structure, in the case of MIT, contributes for the success of the precinct. On the one hand, the importance of the main axes and their visibility within the system of the city of Cambridge, makes the university highly visible, and an important element in the dynamics of the city, not only for its location, but for the emphasis it places on opening its premises to the community and offering several activities and events for both academic and civil community. On the other hand, the seclusion of the inner areas of the precinct, creates the necessary isolation for the development of some activities. The precinct organizes in a very rational way the most public uses in its most visible area, and the most private in its internal areas, that are characteristically difficult to navigate and less intelligible. In opposition to the situation observed in Espoo, its inner structure does not behave as background network because the system is fragmented or discontinuous. It does such for the configuration of its inner structure, purposely designed.

The case of New Haven - a developer precinct - is rather different than the previously described. In this case, the university coincides with the integration core, it is the centre of the urban settlement both in terms of closeness and betweeness, becoming a very attractive place, whether just to cross by on any travel, for the accessibility it provides, or becoming a destination just for its configurational properties.

The case of the city of New Haven, representing the developer precincts, shows the particularity of the university precinct occupying the areas located in the integration core, and also being a part of simultaneously the foreground and the background network. This urban behaviour can be extremely beneficial for the university, for it creates spaces with different characters, that can be used for different purposes. The most visible, with highest through-movement potential, can be a factor of promoting the university, making it highly visible for the exterior community, and creating a character of openness towards the city. The most secluded areas can be used for more private functions, such as residences and dorms, or high security research laboratories. Considering that this type of universities includes all necessary living functions within its premises, it can be an enabler for urban regeneration, since it guarantees the presence of people in the city centre at all times of the day. Table 4 presents a summary of the analysis giving emphasis to the potential movement each type of university precinct has.

Table 4 Syntactic analysis summary

\begin{tabular}{|l|l|l|l|l|l|l|}
\hline PRECINCT TYPE & INTEGRATION & CHOICE & NAIN & NACH & NETWORK & POTENTIAL OF MOVEMENT \\
\hline $\begin{array}{l}\text { AUTONOMOUS } \\
\text { PRECINCT }\end{array}$ & Very Low & High & Very Low & Low & Background & $\begin{array}{l}\text { Low to- and through- } \\
\text { movement potential }\end{array}$ \\
\hline ATTACHED PRECINCT & Low & Low & Low & Low & Background & $\begin{array}{l}\text { Low to- and through- } \\
\text { movement potential }\end{array}$ \\
\hline INNER PRECINCt & Low & Low & Low & High & $\begin{array}{l}\text { Background, } \\
\text { connected to } \\
\text { foreground }\end{array}$ & $\begin{array}{l}\text { High through- movement } \\
\text { potential }\end{array}$ \\
\hline DEVELOPER PRECINCT & Very high & $\begin{array}{l}\text { Very } \\
\text { high }\end{array}$ & Very high & Very high & $\begin{array}{l}\text { Foreground and } \\
\text { background }\end{array}$ & $\begin{array}{l}\text { High to- and through- } \\
\text { movement potential }\end{array}$ \\
\hline
\end{tabular}




\section{Conclusions}

Most of the university precincts assessed are somehow rooted and connected to a city, even when located in secluded locations. Even though, in general, they show low integration values, that reflect on their ability to become highly visible destinations and attraction elements within the urban fabric, they also show higher maximum choice values (the maximum choice value within the campus is usually its main access) than the average of the cities where they are inserted. This points towards a tendency for university campuses that host all functions consentaneous with the constant presence of people to be highly visible in random movement, to be places that can be seen while navigating through cities, but not becoming the targets for travels.

So, if we observe a trend towards achieving a certain degree of seclusion, protecting the academic environment from the city, we can also note a contrasting option of becoming visible to the community in general. These placement features can be an asset used by universities to position themselves as active players in the urban environment, while benefitting from the privacy granted to them by the low integration values.

In a context where universities must reach out to several stakeholders, these characteristics might be very beneficial, helping to create and highlight a posture of openness towards the urban environment that fosters the creation of links and connections, bridging the "academic divide".

More studies should be developed to reinforce or verify these premises, but space syntax has proven a valuable tool to provide insights into key aspects, such as the need to enhance visibility and improve integration, according to the Universities' strategic plans and positioning goals.

\section{References}

Al-Sayed, K., Turner, A., Hillier, B., and lida, S., 2014. Space Syntax Methodology. 2nd ed. London: Bartlett School of Graduate Studies, UCL.

Campos Calvo-Sotelo, P., 2015. Niveles espaciales y dimensión fenomenológica en los ámbitos universitarios. Revista Arquitectonics, 27.

Cannas da Silva, L., 2017. Campus as a City - City as a Campus. A morphological approach to university precincts in urban dynamics. Universidade de Lisboa.

Christiaanse, K. and Hoeger, K., 2007. Campus and the City - Urban Design for the Knowledge Society. 1st ed. Zurich: gta Verlag, ETH Zurich.

Conceição, P. and Heitor, M., 1999. On the role of the university in the knowledge economy. Science and Public Policy, 26 (1), 37-51.

Conceição, P. and Heitor, M., 2001. Universities in the learning economy: Balancing institutional integrity with organizational diversity. In: The Globalising Learning Economy: Major Socio-Economic trends and European Innovation Policies. Oxford: Oxford University Press, 83-96.

Corneil, J. and Parsons, P., 2007. The Contribution of Campus Design to the Knowledge Society: An International Perspective. In: K. Christiaanse and K. Hoeger, eds. Campus and the City - Urban Design for the Knowledge Society. Zurich: gta Verlag, ETH Zurich.

Dober, R.P., 1992. Campus Design. New York, Chichester, Brisbane, Toronto, Singapore: John Wiley \& Sons, Inc.

Duderstadt, J.J., 2002. The future of higher education in the knowledge-driven, global economy of the 21st century. 175th Anniversary Symposium, University of Toronto, 1-26.

Edwards, B., 2003. University Architecture. London: Taylor and Francis.

Engwicht, D., 1992. Towards an eco-city. Calming the traffic. Sydney: Envirobook.

Gibbons, M., Limoges, C., Nowotny, H., Schartzman, S., Scott, P., and Trow, M., 1994. The New Production of Knowledge - The Dynamics of Science and Research in Contemporary Societies. London: SAGE.

Hajrasouliha, A.H. and Ewing, R., 2016. Campus Does Matter - The Relationship of Student Retention and Degree Attainment to Campus Design. Planning for Higher Education, (June), 30-46.

den Heijer, A., 2011. Managing the University Campus - Information to support real estate decisions. Delft: Eburon Academic Publishers. 
Heitor, T. and Pinelo, J., 2006. Axial map of Lisbon.

Heitor, T.V. and Pinelo Silva, J., 2015. A Sintaxe Espacial e o Ambiente Construído - Análise Morfológica. In: V. Oliveira, T. Marat-Mendes, and P. Pinho, eds. O Estudo da Forma Urbana em Portugal. Porto: Universidade do Porto, 147-190.

Heitor, T. and Serra, M., 2016. Lisbon's 11th International Space Syntax Symposium - challenges and prospects for the space syntax field. Journal of Space Syntax, 6 (2).

Hillier B, Hanson J, Peponis J, Hudson J, Burdett R, 1983, "Space syntax: a new urban perspective" Architects Journal 178 (48) 48-63

Hillier, B. and Hanson, J., 1984. The Social Logic of Space. Cambridge: Cambridge University Press.

Hillier, B., Yang, T., and Turner, A., 2012. Normalising least angle choice in Depthmap and it opens up new perspectives on the global and local analysis of city space. Journal of Space Syntax, 3 (2), 155-193.

Indovina, F., 1997. Sinergi Tra Communità e Università. Archivio di Studi Urbani e Regionali, 28/29 (60/61), 85-114.

Kenney, D.R., Dummont, R., and Kenney, G., 2005. Mission and place. Strengthening learning and community trough campus design. Westport, CT: Praeger Publishers.

Knight, R., 1995. Knowledge-based Development: Policy and Planning Implications for Cities. Urban Studies.

Peponis, J., 2016. The Space Syntax of Intelligible Communities. In: R.H. Hunter, L.A. Anderson, and B.L. Belza, eds. Community Wayfinding : Pathways to Understanding. Springer, 35-60.

Seabra, C., 2016. Cambridge Axial Map.

Temple, P., 2009. From Space to Place: University Performance and its Built Environment. Higher Education Policy, 22 (2), 209-223.

Temple, P., 2014. The Physical University: Countours of Space and Place in Higher Education. Paul Temple. Abingdon, New York: Routledge.

Turner, A., 2004a. Depthmap 4: a researcher's handbook. London: Bartlett School of Graduate Studies, UCL. Whyte, W.H., 1980. The Social Life of Small Urban Spaces. New York: The Conservation Foundation.

\section{Resume}

Luísa Cannas da Silva is a licensed architect and holds a PhD in architecture. Her research interests include learning spaces and workspaces with a particular focus on space use analysis, mainly recurring to space syntax methodologies. She is a science communicator who has designed science exhibitions and learning materials, both in university and museum contexts. She currently works as a Learning and Experience Designer for Executive Education at Nova School of Business and Economics.

Teresa V. Heitor is Full Professor in the Department of Civil Engineering, Architecture and Georesources at IST University of Lisbon since 2008. She was the director of the 5-year Master program in Architecture beteween 1999-2004; 2005-2007 and 2009-2016. She is Principal researcher of the Center of Innovation of Territory, Urbanism and Architecture (CITUA), a research unit funded by Fundação para a Ciência e a Tecnologia (FCT). Within CITUA, she coordinates a research line on Knowledge Environments, with a prime focus on educational facilities and innovative learning environments. Research emphasis is placed on the development of: 1) models of form and function capable to predict the implications of new educational demands; 2) self-assessment tools to be applied along educational building process (programming, design \& occupancy stages). An emphasis is also put on advanced training of young researchers, strengthening international networking, participating in joint international and national research projects and keep publishing research results. 